\title{
CrimRxiv
}

\section{Defense, disrespect, and}

\#deadly: A qualitative exploration of precursors to youth violence informed through hospital-based violence prevention program follow up

Katherine B. Snyder ${ }^{1}$, Ashley Raposo-Hadley ${ }^{1}$, Charity Evans ${ }^{1}$, Ashley Farrens ${ }^{1}$, Jennifer Burt ${ }^{2}$, Gaylene Armstrong ${ }^{3}$, Julie Garman ${ }^{3}$, Lindsey Wylie ${ }^{3}$, Mark Foxall ${ }^{3}$

${ }^{1}$ Department of Surgery, University of Nebraska Medical Center,

${ }^{2}$ Munroe Meyer Institute, University of Nebraska Medical Center,

${ }^{3}$ School of Criminology and Criminal Justice, University of Nebraska at Omaha

Published on: May 13, 2021

DOI: 10.21428/cb6ab371.8a624211

License: Creative Commons Attribution 4.0 International License (CC-BY 4.0). 


\section{ABSTRACT}

Youth violence intervention and prevention effects, particularly for gun violence, will be more successful when appropriately informed by the antecedents and context of violence. Youth violence is guided by social and cultural norms that are shifting with the rise of technology. Bullying, gang violence, and self-directed violence is increasingly found to occur in the online space influencing peer groups across contexts. Through focus groups with youth at risk for violence and victimization, this study finds three themes emerge as common precursors to violence: defense of self or others, disrespect of self or family, and threats or disrespect related to social media platforms. Youth violence prevention programs can be more effective through use of a social cognitive intervention framework to address violence through building knowledge, attitudes, and skills needed for violence reduction informed by precursors to violence found in this analysis.

Homicide rates are the third leading cause of death for young people aged 15-24 (CDC, 2018), disproportionately effecting ethnic and racial minorities in our community. Thirteen young people are victims of homicide every day, and emergency departments treat 1,300 additional youth for non-fatal violence related injuries. In 2019, 14,414 homicides with firearm occurred in the United States. In addition to a deleterious impact on public health, ongoing violence is costly. The U.S. spends more than $\$ 21$ billion in combined medical expenses and lost productivity costs due to violent injuries (CDC 2018; David-Ferdon, Vivolo-Kantor, et.al. 2016; Kann, McManus, et.al. 2018).

To reduce and prevent violence related injuries, particularly youth gun violence, researchers underscore that we need to better understand the antecedents of violence and the context within which violence occurs (Teplin et al., 2021). Prior research has established that both individual and community factors influence an individuals' likelihood of experiencing and perpetrating violence, with adverse childhood experiences most robustly influencing violence (Leban \& Gibson, 2020). Individual differences that influence involvement in youth delinquency include, but are not limited to substance use, antisocial attitudes, history of victimization, impulsivity, and poor school performance (Farrington, 2003; Farrington, Loeber, \& Ttofi, 2012; Herrenkohl, Farrington, Brewer, Catalano, Harachi, \& Cothern, 2000). Interpersonal relationships that youth have with peers, parents, and other adults (e.g., teachers) and the nature and quality of those relationships also matter. Youth who have frequent interactions with delinquent peers or belong to gangs are more likely to be victims 
themselves and more likely to victimize others (Farrington et al., 2012; Herrenkohl et al., 2000). Within the community, interactions between individuals in formal institutions such as schools, and informally within neighborhoods, result in varying levels of risk and opportunity for youth engagement in violence (Farrington et al., 2012; Herrenkohl et al., 2000; Sampson, Moreno, \& Gannon-Rowley, 2002; Toomey, Erickson, Carlin, Lenk, Quick, Jones, \& Harwood, 2012). Dynamics in these various contexts and the potential for youth violence are guided by social and cultural norms regarding violence, but also present violence prevention and intervention opportunities (Herrenkohl et al., 2000; Egerter, Barclay, Grossman-Kahn, \& Braveman, 2011; Petrosino, Turner, Hanson, Fronius, \& Campie, 2014).

Adding to the complexities that exist in relationship dynamics within these various contexts is the increased use and availability of technology. Communication between youth has changed to include social media platforms that shape interactions and relationships between individuals, within groups as well as between groups. New social and cultural norms inform behavioral expectations in these realms. Violations of normative behavior may be perceived as inappropriate, disrespectful, or even rise to the level of perceptions as bullying or threatening behaviors. When behaviors target specific youth, negative psychological impacts for victimized youth result (Marciano, Schulz \& Camerini, 2020) and may lead to retaliatory behavior.

Researchers note the Internet has changed opportunities for crime and deviance, much as it has changed other aspects of social life (Pyrooz, Decker \& Moule, 2015). Social media applications and online platforms originally created for prosocial engagement transcending geographical location, now facilitates urban-based youth violence. Bullying, gang violence, and self-directed violence is increasingly found to occur in the online space influencing peer groups across contexts (Patton, Hong, Ranney, Patel, Kelley, Eschmann, \& Washington, 2014). In schools, the prevalence of cyberbullying can range from targeted harassment to threats of violence (Ansary, 2020) with such cyber-victimization, in turn, resulting in retributive violence (Cardwell et al., 2021; Cho et al., 2017). On the streets, youth at risk for engaging in violence include active gang members who use social media to plan and engage in delinquency, incite violence, or support local substance use and distribution (Pyrooz, Decker \& Moule, 2015). This use of social media, known as Internet banging (Patton, Eschmann \& Butler, 2013; Patton, Eschmann, Elsaesser, \& Bocanegra, 2016), led to serious injury and homicide in some instances (Patton, Lane, Leonard, Macbeth, \& Smith Lee, 2017). 
Accompanying the movement of offending and victimization to the online environment is the expansion of deviant violence-oriented groups-including youth gangs-in online settings. A relatively new trend among youth living in violent urban neighborhoods is the utilization of social networking sites such as TikTok, Twitter, Instagram, SnapChat and other applications to brag about violence, make threats, and recruit gang members. Further, these same social media platforms are also used to incite violence within communities by taunting rival gangs, posturing and boasting about violent events.

The focus on gang member use of social media is particularly relevant for violence intervention and prevention efforts as these individuals are among the highest risk youth in most communities. Pyrooz and colleagues (2015) gathered social media use data from 585 respondents, including 418 current and former gang members in five cities. They concluded gang members use the Internet and social networking sites as much, if not more, than their non-gang counterparts. Importantly, gang members have a greater overall propensity for online crime and deviance than former and non-gang respondents. Although Pyrooz et al. found the Internet was more commonly used for symbolic purposes than instrumental (i.e., monetary) gain, other researchers disagree. Patton, Patel, Hong, Ranney, Crandall, and Dungy (2017) analyzed 8.5 million Detroit gang members' tweets from January 2013 to March 2014 to assess whether they contained gang related terminology. They found that $4.7 \%$ of gang-affiliated user tweets consisted of terms related to violence and crime. Violence and crime-related communications fell into four main categories: (a) beefing (267,221 tweets), (b) grief (79,971 tweets), (c) guns (3,551 tweets), and (d) substance use and distribution $(47,638$ tweets). Patterns in violent and criminal communication that may be helpful in predicting future delinquent activities were identified, which has implications for violence prevention research, practice, and policy.

\section{A Trauma and Context Informed Approach to Violence Prevention}

Programs targeting youth violence prevention are oftentimes reactive, focusing on scaring adolescents out of unwanted antisocial behavior. Yet, examinations of "Scared Straight" programs have found these types of programs to be ineffective and even lead to higher rates of violent and criminal offenses in youth who participate in the program (Dodge, 2001; Petrosino, Turpin-Petrosino, et. al., 2013). One reason these programs are ineffective is they fail to account for the relationship between the youth's contextual environment, their adverse childhood experiences including trauma, and their current behavioral issues (Dodge, 2001; Petrosino, Turpin-Petrosino, et. al. 2013). 
To counteract prevention program deficits, Cradle to Grave (C2G), a hospital-based violence prevention program was implemented at Temple University Hospital and preliminary data found the program was successful in preventing youth violence (Goldberg, Toto, et al., 2010). Temple University Hospital's hospital based C2G violence prevention program recreates the experience of an adolescent who died because of a gunshot. The two-hour long program walks participants through the last moments of a 16-year-old boy's life in a trauma center, combining a classroom and hands-on learning approach that uses participant volunteers to demonstrate procedures experienced by the gunshot victim, asking them to reflect upon the broader implications of youth violence. An evaluation of the program found a reduction in violent beliefs one month following participation in the program and the results were observed most frequently in those participants who were exposed to the greatest levels of violence (Goldberg, Toto, et al., 2010).

Modeled after C2G, Dusk to Dawn (D2D), a hospital-based youth violence prevention program was developed and implemented in a Midwestern city. D2D follows a social cognitive intervention framework by addressing violence at an individual level through knowledge, attitude, and skills needed for violence reduction. This paper uses data and insight gathered from D2D participants to better understand the current context of youth violence and help inform violence prevention program efforts. Several quantitative studies have been published to understand the context of youth violence, yet few qualitative studies have been conducted more recently when factors such as social media and online aggression are increasingly impactful in initiating violence or retributive violence. Violence is a multifactorial issue, with no single factor leading to violent behavior in youth; therefore, a qualitative approach will enhance a deeper understanding of the associated complexities, systems, and contexts to better guide future youth violence prevention efforts.

The focus of this study is to gain an understanding of the perceptions and contextual factors that lead to youth involvement in violence. This research extends prior work on youth violence by incorporating an in-depth examination of themes related to youth violent victimization and perpetration. It is crucial to engage youth from communities experiencing violence as participants in both hospital-based violence prevention activities and as research participants. Their perspectives will strengthen future violence prevention and intervention programming and approaches. 


\section{Method}

The present study utilized data collected from a community sample of youth who participated in a hospital-based violence prevention program. Data from five focus groups with D2D participants were analyzed with a goal of determining themes that emerged from the discussions. The priority was to understand the socio-cultural context in which youth violence occurs from the youth perspective. This information could be used to facilitate improvements and long term follow up of youth in violence prevention programs.

\section{Sample}

The sample for this study was comprised of youth who participated in the D2D program, and the focus group discussion held on subsequent dates (See Snyder et al. 2020 for discussion of D2D program). All focus group participants were youth from the Boys and Girls Clubs of the Midlands (BGC), lived in an urban area, and were between 12 and 18 years of age. Community-based organizations, probation, or an adult community member who perceived a youth to be at risk for violence perpetration or victimization may refer a youth to the BGC. While we often conceptualize youth violence as a "big city" problem, less populous cities across the nation continue to be afflicted including metro area of Omaha, Nebraska (population: 835,000 in 2020). Most victims of violence reside in North or Southeast Omaha, areas with historically high proportions of ethnic and racial minorities, low socio-economic status, food and housing insecurity, and below average national high school graduation rates (United States Census Bureau, 2018).

\section{Procedure}

Prior to D2D and the focus groups, researchers obtained parent or guardian consent for all youth. To maintain participant anonymity and encourage open discussion, no demographic indicators were collected from the youth. Upon program completion, youth received a certificate of completion. Program staff provided snacks during discussion but no other participation or monetary incentives.

\section{The Dusk to Dawn Program (D2D)}

$D 2 D$ is a $2 \frac{1}{2}$ hour hospital-based youth violence prevention program developed using evidence-based anti-gang prevention principles. D2D is facilitated by a team comprised of a credible messenger, a trauma surgeon, staff facilitator, BGC team leader (familiar to the kids), and the mother of the victim discussed. Youth participants meet the 
program staff at a local hospital, which is a Level 1 trauma center. During the first 15 minutes of the program, program facilitators guide youth through the hospital emergency department and recount the last moments of a young gunshot victim's life in the trauma bay. The account is based on the real story of a young man from the local area who lost his life to gun violence. This experience serves as a catalyst for a 2-hour, 15-minute in-depth discussion that follows. Discussions were led by a "credible messenger," a person with relevant life experience and "social capital" that gives them authority to challenge and transform the thinking, attitudes, and behaviors of others. A credible messenger uses an interpersonal approach to communicate with youth such that they are likely to perceive the credible messenger as a trustworthy and relatable individual, and perceive the information shared as credible (see Asfaw, Morankar, Abera et al., 2019; Wical, Richardson \& Bullock, 2020). Discussion topics in D2D include the youths' understanding of risk and protective factors, perceptions of violence, and challenges common beliefs about violence.

\section{Focus Groups}

For the purposes of this study, after the D2D program, focus groups were held at five different BGC in the metropolitan area. Each focus group was comprised of between five and ten youth. Focus group sessions were approximately one hour in length. The research team developed and utilized a semi-structured interview guide to prompt discussion about a variety of topics including general awareness of violence, typical response to violence, and violence risk and protective factors. The focus groups were audio-recorded and transcribed using a professional transcription service.

\section{Analytical Strategy}

A thematic analysis using Braun and Clark's (2006) six phase procedure was performed. These phases include familiarization with data, generating initial codes, searching for themes, reviewing themes, defining, and naming themes, and reporting. Two independent coders reviewed and coded the transcripts. Throughout the analysis, coders discussed and reviewed emerging themes. Although coding disagreements rarely occurred, coders discussed differences and reached consensus before proceeding. Codes, notes, themes, and excerpts were entered and tracked using Dedoose online software version 8.0.35.

As typical with qualitative research methodology, reliability is achieved when the data analysis reaches a saturation point, meaning the analysis reaches a point where the data offers no new information (Dreher, 1994). Themes were identified after the first 
few transcripts were coded and were further confirmed through the analysis of subsequent transcripts. The present analysis was based on data drawn from five independent focus groups held in five distinct areas of Omaha to reduce potential bias and increase overall generalizability of the study.

The present analysis made use of the constructivist framework, which focuses on experience as socially produced (Fahy \& Harrison, 2005). The constructivist framework is most appropriate given the socio-cultural context of violence. The first goal of this research was to highlight the voices of the youth living these experiences. Secondly, to describe the contexts that allow for violent perpetration and victimization among at-risk youth who participated in a hospital-based youth violence prevention program. Finally, to present these findings in a purposeful manner that will support future avenues of focus and expansion for youth violence prevention programming and long term follow up.

\section{Results}

Three primary themes emerged from the analysis of focus group discussions including Defense, Disrespect, and \#deadly. First, the theme of defense includes concepts related to perpetration of violence as a means of self-defense. Second, disrespect included discussion related to the role of perceived disrespect in situations of violent perpetration. Finally, \#deadly included youth perceptions of violence in social media and the role of social media in promoting violent behavior.

\section{Defense}

Violence as a means of self-defense emerged as a primary theme in discussions among focus group participants. Many participants reported that engagement in violence with peers was the result of situations in which other youth-initiated fistfights, forcing the participant to self-defend with violence. One participant says, "if they throw the first punch that's when you...that's when you fight." Most participants agreed that violence as a means of self-defense was generally acceptable. As most participants agreed that violence in self-defense was justified, focus group moderators further prompted participants to discuss their views related to any potential positives to violence. A participant responded, "The good one is like defending yourself because like you know you need to do it, but like you're trying to protect yourself from another person, and in the bad way is like doing it to hurt someone." Violence as a defense was perceived in a positive light by this participant as it was a way to stand up for and protect themselves. Further, the sentiment to fight back was so strong that it emerged even 
when the conversation topic was about stepping in while others were fighting. When the moderator questioned the focus group participants if they were scared to break up a fight, one participant replied, "Two people throwing punches? If I get hit, I've got to swing back." This behavior suggests youth are willing to engage in violence even when they were not the initial focus of the fight and perceive this involvement to be defensive violence.

A benefit of the Dedoose software used for the analysis is that it allows researchers to track code co-occurrence, highlighting topics that were often discussed in unison. In our analyses, parental approval of violence in self-defense, specifically mothers were most often brought up when the discussion revolved around violence stemming from self-defense. A participant recalls,

"If like...if you're just cussing at me or like yelling at me, my parents like...like know that I wouldn't do anything, I would just like walk away, but if it's like somebody hits me then I have to fight like...I have to fight back, or else when I get home and they see that I'm....that I got beat up, they're going to beat me up next... Yeah...that's the one rule. You can fight back, or you come home beat up, she's going to hit you."

Additional participants added, "My mom told me, she said if anybody hit me, hit them back." and "My mom is usually like people can say whatever they want to but if they hit you then you have to fight back. That's what she says." Although almost all parental conversation regarding self-defense was exclusive to mothers, one participant spoke about their father. A focus group moderator asked, "But what if...what if someone does hit you and you decide I don't want to fight this person, and you don't hit them back, then what will your family think?" to which the participant responded, "My dad thought he's soft." This suggests that self-defense is a learned behavior and that interactions with and perspectives of parents, especially mothers, are vital to the process by which youth learn expectations in responding to real or perceived threats of violence. Overall findings that emerged related to the theme of defense, suggest that these youth learned over time that violence is a means of self-defense or defense of another was acceptable, justified, and in many cases, an expected behavioral norm.

\section{Disrespect}

Another prevalent theme that emerged was violence used in situations that stemmed from the perceived disrespect of the youth. Youth often named disrespect as a risk factor for violence along with drugs, gang involvement or "gangbanging," and guns. 
When youth were provided with a hypothetical situation involving disrespect, they often presented violent solutions. Focus group moderators posed the following scenario to participants:

"So if [name redacted] says he's got to be involved, he's got to get in that situation, does anyone think it's okay to say I don't want to be...I don't want to get in a fight, you can say what you want, I'm not going to do it?”

A focus group participant responded, "Me? All I got to do is fight and just let them know, you don't disrespect me like that, and if it turns into a fight, it turns into a fight."

Although most participants mentioned disrespect as an absolute antecedent to aggressive behavior or violence, some youth felt disrespect towards their family was an even stronger promoter of violence. A moderator asks:

"So [name redacted] you touched on this when you people disrespect you, it's different from when people disrespect your family? How do you guys respond? You kind of told us already, but how would you respond if someone disrespected you versus disrespected your family?"

A participant recalls,

"I mean when somebody disrespects me, like I don't ... it just makes...it makes me laugh, but when it's like...if it becomes serious, I'm thinking for most of us it becomes serious when somebody starts talking about our family, especially the people that we have lost..."

The same sentiment emerged with verbal aggression as a potential response. One participant says, “I don't run my mouth. I don't...I don't...the only time I run my mouth is when someone starts disrespecting me, especially my family." Other participants agree, one says, “It doesn't...it really doesn't matter where you fight, you disrespect somebody's family member....everything's out the window." and another participant adds, "Yeah, you always have to have respect for your parents, especially how much they do for you and you, and you always got to like especially if someone tries to disrespect them." In sum, findings in relation to the theme of disrespect suggest that feelings and situations involving disrespect often led to violent interactions both physical and verbal. This form of reactive violence is especially evident when disrespect involves family members. 


\section{\#deadly}

Social media and engagement in online spaces is a critical component of the social lives of today's youth. Instant, unsupervised, and often anonymous, social media can become a dangerous facilitator in youth violence offline. A participant recalls,

"I feel like a lot of the people our age, they get most of their information from social media so like if there's a fight, that's where they get it from. There's like no...there's a lot of things on social media that people get information from and the parents don't even know about, they just do their own thing."

Youth described feeling exposed to their peers and under pressure to react when others instigated them on social media. A participant says,

"I agree with that because that kind of bullshit on social media aspect like, people are quick to like, you know, on video, or whether its, you know, on Instagram, Snapchat, or whatever, like you got to do something, and if you don't, like, even if you were doing something, everybody else going to think that you backed down, you was soft or you was scared. Sometimes, like a lot of kids will feel pressure to do that. So, I think, I actually see that."

Focus group moderators further prompted participants to discuss the role social media plays in offline violence, participants responded, "Yeah." and "It's a...everyone can see it. Yeah, everyone can see it." One participant went as far as to describe online instigation as real to youth as in-person violence. This participant says, "It's like if there's two people that would fight, there's going to be a lot of people surrounding them and they like fight, fight..." These findings suggest that for these youth, what happens online is perceived as just as real and a threat as in person aggression. Although social media seems to be a critical component to violent circumstances, youth often have no or little guidance on how to handle these situations. While normative expectations are developing in terms of acceptable aggressive reactions, techniques to diffuse disrespect or disagreements in the social media environment are lacking among youth.

While youth learned expectations regarding in person aggression from parents, they do not have parental guidance in the virtual environment or have parental support and resources in diffusing an online situation. Participants described the social media patterns of their parents being different from their own, often leading to a lack of understanding from their parents. A moderator asked, "What do you guys think, or what do you wish that adults or like your parents or teachers or just adults, in general, 
knew about youth violence, about violence with your guy's age?" To which a participant responded, "It's different." and another participant adds, "Social media especially."

Findings related to social media, \#deadly, suggest that offline violent interactions often begin in an online environment. Threats received via social media are often perceived to be just as legitimate and serious as in person threats, and responses to them are also perceived as necessary and justified. Further, the age gap between youth and the adults in their lives, as it relates to the digital world, leave youth unguided, unsupervised, and often misunderstood.

\section{Discussion}

As youth violence is a complex issue influenced by a multitude of factors, the prevention of such violence is an equally complicated problem facing communities. The purpose of this study was to build upon prior research through a more in-depth examination of factors that emerged as relevant for violent perpetration and victimization among focus groups of youth who had previously participated in a hospital-based violence prevention program. Three primary themes, defense, disrespect, and \#deadly emerged from discussions with these focus group participants. Youth recalled the relationship between past perpetration in violence and how these related to situations in which they felt compelled to defend themselves or someone else through violent means. As interactions do not occur in a vacuum, situations involving youth violence often arose when a youth perceived they (or a family member) had been disrespected by another. Notions of the necessity to retaliate against disrespect through violent means was often linked by youth to interactions they had with parents, especially with their mothers. Finally, and perhaps most importantly for future youth violence prevention efforts, while these interactions often begin in an online environment, they frequently lead to offline violent behavior. The greater use of social media by an increasingly younger population, combined with a lack of inappropriate supervision, has implications for further escalating rates of youth violence perpetration and victimization when they do not have the skills to diffuse these negative interactions.

Follow-up research with program participants offers the ability to further our understanding of factors that initially lead youth into violence as well as the effects of this type of violence prevention program. Although the latter is beyond the scope of the present study, qualitative examinations of focus group data allow researchers to gain a more in depth understanding of the factors and social context that encourage 
youth violence offers opportunities to improve upon youth violence prevention programs.

This study is not without limitations. As the data for this study were derived from focus groups, participants may have responded to questions differently than they would have if they had been interviewed individually. Another disadvantage of using focus groups relates to observer dependent biases, or the tendency of participants to agree with those moderating the group discussion. Finally, the small sample size and lack of demographic information due to assurance of confidentiality prevents generalizability of results to larger populations of youth.

\section{Implications}

The findings of this study have implications for policy and practice regarding youth violence, particularly gun violence. Youth violence is not just a problem for law enforcement, it is also a public health problem that must be studied and intervened from multiple perspectives. Much quantitative work, and some qualitative work has been undertaken to examine perspectives of youth regarding violence and intervention programs. More qualitative work on youth violence through a public health and criminological lens is needed. Here, we examined the hospital-based D2D program that youth attended prior to the focus groups followed a social-cognitive framework for youth violence prevention that are specifically designed for youth. Prior studies find the younger participants are when they begin prevention programming, the better chance of successful prevention (Greene, 1998; Slaby, 1998). Ideally, a prevention program would reach all youth in our communities, rather than restricting it to youth considered at risk for violence. Programs, like D2D, are typically designed to introduce ways for youth to alternative viewpoints on violence and conflict, discuss avenues to that would encourage conflict avoidance and management skills by improving interpersonal and problem-solving skills to work towards mutually beneficial solutions (Greene, 1998; Slaby, 1995). D2D incorporates these considerations into the curriculum as well as in active learning exercises that work towards changing attitudes and beliefs regarding non-violent solutions to conflicts. As prior research was lacking in program follow-up, this study utilizes a qualitative approach to gather focus group data and aimed to give youth a voice with a seat at the table and further explore antecedents to youth violence, particularly regarding incidents stemming from negative social media interactions. Our findings underscore the changing landscape of youth interactions that may lead to violence and the importance of using qualitative approaches to guide policy and practice. Our findings are exploratory given the lack of 
research in this area. Future research should further examine the process by which youth violence perpetration and victimization occur and the importance of themes related to perceptions of disrespect, desire for self-defense, and the influence of social media in these interactions. Further, youth violence prevention and treatment programs should seek to incorporate these themes into treatment strategies.

\section{References}

Ansary, N. S. (2020). Cyberbullying: Concepts, theories, and correlates informing evidence-based best practices for prevention. Aggression and Violent Behavior, 50, 101343.

Asfaw, S., Morankar, S., Abera, M., Mamo, A., Abebe, M., Abebe, L., Bergen, N., Kulkarni, M. A., \& Labonte, R. (2019). Talking health: Trusted health messengers and effective ways of delivering health messages for rural mothers in Southwest Ethiopia. Archives of Public Health, 77, https://doi.org/10.1186/s13690-019-0334-4.

Braun, V., \& Clark, V. (2006). Using thematic analysis in psychology. Qualitative Research in Psychology, 3, 77-101. https://doi.org/10.1191/1478088706qp063oa

Cardwell, S. M., Bennett, S., \& Mazerolle, L. (2021). Bullying victimization, truancy, and violent offending: Evidence from the ASEP truancy reduction experiment. Youth Violence and Juvenile Justice, 19, 5-19.

Centers for Disease Control and Prevention, National Center for Injury Prevention and Control. (2018). Web-based Injury Statistics Query and Reporting System (WISQARS) [online] 2018. Retrieved from www.cdc.gov/injury.

Cho, M. K., Kim, M., \& Shin, G. (2017). Effects of cyberbullying experience and cyberbullying tendency on school violence in early adolescence. The Open Nursing Journal, 11, 98-107.

David-Ferdon, C., Vivolo-Kantor, A. M., Dahlberg, L. L., Marshall, K. J., Rainford, N. \& Hall, J. E. (2016). A Comprehensive Technical Package for the Prevention of Youth Violence and Associated Risk Behaviors. Atlanta, GA: National Center for Injury Prevention and Control, Centers for Disease Control and Prevention.

Dodge, K. A. (2001). The science of youth violence prevention: Progressing from developmental epidemiology to efficacy to effectiveness to public policy. American Journal of Prevention Medicine, 20, 63-70. 
Dreher, M. (1994). Qualitative research methods from the reviewer's perspective. In J. Morse (Ed.), Critical Issues in Qualitative Research Methods (pp. 281-297). London: Sage.

Egerter, S., Barclay, C., Grossman-Kahn, R., \& Braveman, P. (2011). Exploring the social determinants of health: Violence, social disadvantage and health. Princeton: Robert Wood Johnson Foundation. Retrieved from http://www.rwjf.org/content/dam/farm/reports/issue_briefs/2011/rwjf70452

Fahy, K., \& Harrison, K. (2005). Constructivist research: Methodology and practice. In G. Tenenbaum \& M.P. Driscoll (Eds.) Methods of Research in Sport Sciences: Quantitative and Qualitative Approaches (pp.660-701). Oxford: Meyer and Meyer Verlag.

Farrington, D. (2003). Key results from the first forty years of the Cambridge Study in Delinquent Development. In T. Thornberry, \& M. Krohn (Eds.), Taking Stock of Delinquency: An Overview of Findings from Contemporary Longitudinal Studies. (pp. 137-183). New York: Kluwer Academic/Plenum.

Farrington, D. P., Loeber, R., \& Ttofi, M. M. (2012). Risk and protective factors for offending. In B. Welsh, \& D. Farrington (Eds.) The Oxford handbook of crime prevention (pp. 46-69). New York: Oxford University Press.

Goldberg, A. J., Toto, J. M, Kulp, H. R., Lloyd, M. E., Gaughan, J. P., Seamon, M. J., \& Charles, S. P. (2010). An analysis of inner-city students' attitudes towards violence before and after participation in the "Cradle to Grave" Programme. Injury, 41, 110-5.

Greene, M. B. (1998). Youth violence in the city: The role of educational interventions. Health Education \& Behavior, 25, 175-93.

Herrenkohl, T. I., Farrington, D. P., Brewer, D., Catalano, R. F. Harachi, T. W., \& Cothern, L. (2000). Predictors of Youth Violence. Department of Justice, Office of Justice Programs, Office of Juvenile Justice and Delinquency Prevention. Washington, D.C.

Kann, L., McManus, T., Harris, W. A., Shanklin, S. L., Flint, K. H., Queen, B., Lowry, R. et al. (2018). Youth Risk Behavior Surveillance - United States, 2017. Morbidity and Mortality Weekly Report. Surveillance summaries (Washington, D.C.: 2002) 67, 1-114.

Leban, L. \& Gibson, C. L. (2020). The role of gender in the relationship between adverse childhood experiences and delinquency and substance use in adolescence, 
Journal of Criminal Justice, 66, https://doi.org/10.1016/j.jcrimjus.2019.101637.

Marciano, L., Schulz, P. J., \& Camerini, A. (2020). Cyberbullying perpetration and victimization in youth: A meta-analysis of longitudinal studies. Journal of ComputerMediated Communication, 25, 163-181.

Patton, D. U., Eschmann, R. D., \& Butler, D. A. (2013). Internet banging: New trends in social media, gang violence, masculinity, and hip hop. Computers in Human Behavior, 29(5), A54-A59. https://doi.org/10.1016/j.chb.2012.12.035

Patton, D. U., Hong, J. S., Ranney, M., Patel, S., Kelley, C., Eschmann, R., \& Washington, T. (2014). Social media as a vector for youth violence: A review of the literature. Computers in Human Behavior, 35, 548-553.

Patton D. U., Eschmann, R. D., Elsaesser, C., \& Bocanegra, E. (2016). Sticks, stones and Facebook accounts: What violence outreach workers know about social media and urban-based gang violence in Chicago. Computers in Human Behavior, 65, 591-600.

Patton, D. U., Lane, J., Leonard, P., Macbeth, J., \& Smith Lee, J. R. (2017). Gang violence on the digital street: Case study of a South Side Chicago gang member's Twitter communication. New Media \& Society, 19, 1000-1018. https://doi.org/10.1177/1461444815625949

Patton, D. U., Patel, S., Hong, J. S., Ranney, M., Crandall, M., \& Dungy, L. (2017). Tweets, gangs, and guns: A snapshot of gang communication in Detroit. Violence \& Victims, 32, 919-934.

Petrosino, A., Turpin-Petrosino, C., Hollis-Peel, M. \& Lavenberg, J.G. (2013). Scared Straight and other juvenile awareness programs for preventing juvenile delinquency: A systematic review. Campbell Systematic Reviews, 9, 1-55.

Petrosino, A., Turner, H., Hanson, T. L., Fronius, T., \& Campie, P. E. (2014). The Impact of the Safe and Successful Youth Initiative (SSYI) on City-Level Youth Crime Victimization Rates. An Interrupted Time Series Analysis Wwth Comparison Groups. Boston, MA: Massachusetts Executive Office of Health and Human Services.

Pyrooz, D., Decker, S., \& Moule, R. K. (2015). Criminal and routine activities in online settings: Gangs, offenders, and the internet. Justice Quarterly, 32, 471-499.

Sampson, R. J., Morenoff, J. D., \& Gannon-Rowley, T. (2002). Assessing "neighborhood effects": Social processes and new directions in research. Annual Review of Sociology, 
$28,443-478$.

Slaby, R. G. (1998). Preventing youth violence through research-guided intervention. In P. K. Trickett, \& C. J. Schellenbach (Eds.) Violence against Children in the Family and the Community (pp. 371-99). Washington, DC: American Psychological Association.

Slaby, R. G. (1995). Early Violence Prevention: Tools for Teachers of Young Children. Washington, DC: National Association for the Education of Young Children.

Snyder, K. B., Farrens, A., Raposo-Hadley, A., Tibbits, M., Burt, J. , Bauman, Z. M., \& Evans, C. H. (2020). Dusk to Dawn. Journal of Trauma and Acute Care Surgery, 89(1), 140-144. https://doi: 10.1097/TA.0000000000002678.

Teplin, L., Meyerson, N. S., Jakubowski, J. A., Aaby, D. A., Zheng, N., Abram, K. M., \& Welty, L. J. (2021). Association of firearm access, use, and victimization during adolescence with firearm perpetration during adulthood in a 16-year longitudinal study of youth involved in the juvenile justice system. JAMA Network Open, https://doi:10.1001/jamanetworkopen.2020.34208

Toomey, T. L., Erickson, D. J., Carlin, B. P., Lenk, K. M., Quick, H. S., Jones, A. M., \& Harwood, E. M. (2012). The association between density of alcohol establishments and violent crime within urban neighborhoods. Alcohol Clinical and Experiential Research, $36,1468-1473$.

Wical, W., Richardson, J., \& Bullock, C. (2020). A credible messenger: The role of the violence intervention specialist in the lives of young black male survivors of violence. Violence and Gender, 7, 66-69. 